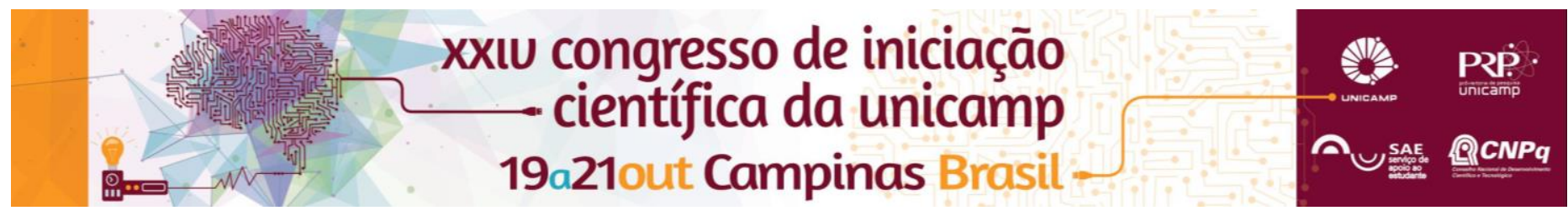

\title{
PREPARO DE MATRIZES OBTIDAS A PARTIR DE POLÍMEROS NATURAIS PARA LIBERAÇÃO CONTROLADA DE FÁRMACOS.
}

\author{
Bruno T. Tomoda*, Marisa M. Beppu, Mariana A. de Moraes.
}

\begin{abstract}
Resumo
A fibroína e o alginato são polímeros naturais obtidos de casulos de bichos-de-seda e da parede celular de algas marrons, respectivamente. Ambos apresentam grande potencial de aplicação na área de biomateriais, já que apresentam elevada biocompatibilidade. O objetivo desse trabalho foi a incorporação do fármaco sulfadiazina de prata em blendas de alginato e fibroína. As matrizes foram caracterizadas por espectroscopia de infravermelho por transformada de Fourier (FTIR) e foram analisadas sua estabilidade em água. Devido ao interrupmento no projeto após 4 meses, não foi possível realizar as atividades restantes. Esperava-se no final do projeto obter um dispositivo de liberação controlada com propriedades adequadas para aplicação como curativo em queimaduras da pele.
\end{abstract}

\section{Palavras-chave:}

Biopolímeros; Biomateriais; Liberação controlada; Queimaduras.

\section{Introdução}

A fibroína de seda é uma proteína presente nos casulos de bichos-de seda da espécie Bombyx mori e é constituída principalmente por alanina, glicina e serina². $\mathrm{O}$ alginato é um polissacarídeo obtido da parede celular de algas marinhas marrons e de bactérias. Ambos os polímeros apresentam elevado potencial como biomaterial, auxiliando na cicatrização de feridas ${ }^{2}$.

Neste projeto de pesquisa, buscou-se estudar a incorporação de sulfadiazina de prata em matrizes poliméricas (blendas) através da combinação dos polímeros naturais fibroína e alginato, visando a utilização como dispositivo de liberação controlada de fármacos.

\section{Resultados e Discussão}

No preparo das blendas de fibroína de seda e alginato de sódio, foi utilizado a proporção fibroína:alginato 75:25.

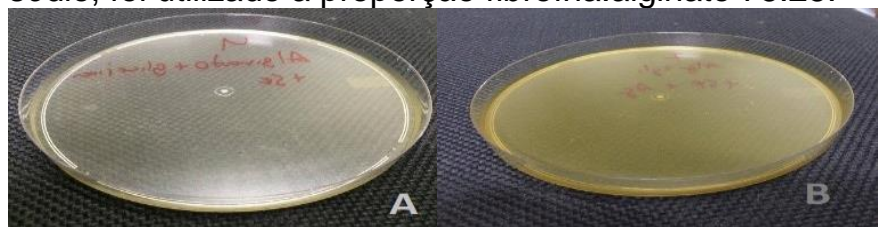

Figura 1 - A) Blenda de alginato/fibroína; B) Blenda de alginato/fibroína com sulfadiazina de prata incorporada na solução.

Em espectroscopia de infravermelho (FT-IR), foram analisadas membranas de fibroína, de alginato e blendas de alginato/fibroína com e sem incorporação de sulfadiazina de prata.

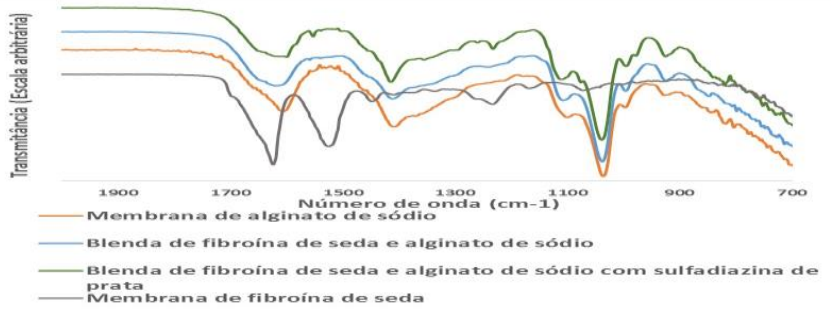

Figura 2 - Espectroscopia de infravermelho das membranas de fibroína, de alginato e blendas de alginato/fibroína com e sem incorporação de sulfadiazina de prata.

Os espectros indicam que as blendas de alginato/fibroína apresentam picos característicos das membranas de fibroína e de membranas de alginato. Também, pode-se observar que no espectro da blenda com o fármaco incorporado, há dois picos, em $1560 \mathrm{~cm}^{-1}$ e $1230 \mathrm{~cm}^{-1}$, que o diferenciam da blenda e são característicos da sulfadiazina de prata $^{3}$, indicando a incorporação efetiva da sulfadiazina na blenda.

No teste de estabilidade, a membrana de alginato de sódio $e$ as blendas desestabilizaram quando foram imersas em água destilada, ou seja, desintegraram após um pequeno período de tempo em contato com a água. Apenas a membrana de fibroína de seda se manteve estável, devido a uma reticulação realizada anteriormente com etanol $70 \%$, para induzir a conformação de folha- $\beta$. O tratamento para estabilização utilizando etanol $70 \%$ foi testado para as outras matrizes, mas não foi efetivo.

$\mathrm{Na}$ adição do fármaco à blenda, esperava-se um resultado semelhante ao projeto de iniciação científica anterior, onde a adição do fármaco induzia a conformação mais estável da matriz polimérica, sendo possível eliminar uma etapa de produção do biomaterial. Entretanto, tal resultado não foi obtido nesse projeto, possivelmente pela troca do fármaco, de diclofenaco de sódio para sulfadiazina de prata, e pela adição do alginato como matéria prima para a matriz polimérica. A interação fármaco-matriz polimérica precisaria ser melhor estudada a fim de se obter um resultado semelhante ao esperado.

\section{Conclusões}

Os aspectos visuais da matriz polimérica indicaram que a sulfadiazina de prata foi incorporada com sucesso à blenda e, os espectros de infravermelho sinalizam o mesmo resultado. Entretanto, a matriz polimérica com o fármaco incorporado apresentou problemas de instabilidade em água, necessitando de uma etapa adicional de reticulação, que não foi possível de ser definida.

\section{Agradecimentos}

Ao $C N P Q$ e SAE, pelo apoio financeiro.

$\overline{{ }^{1} \mathrm{G} . \text { H. Altman et al. Biomaterials }}$ 2003, 24, 401.

${ }^{2}$ M. A. Moraes, Tese de Mestrado em Engenharia Química, Faculdade de Engenharia Química, Universidade Estadual de Campinas, 2010.

${ }^{3}$ S. V. Ghodekar, S. P. Chaudari, M. P. Ratnaparakhi. International Journal of Pharmacy and Pharmaceutical Sciences, v. 4, 2012. 